\title{
Augusto y el control de los territorios pirenaicos
}

\author{
Oriol Olesti VILA \\ Universitat Autònoma de Barcelona \\ Oriol.Olesti@uab.cat
}

\section{RESUMEN}

La ocupación de las áreas pirenaicas en época de Octavio-Augusto, especialmente a partir de la derrota de los ceretanos en el año 39 a.C., ha sido considerada como el punto de partida del proceso de romanización de estos territorios, frecuentemente percibidos como marginales. Sin embargo, los últimos trabajos arqueológicos en el Pirineo Oriental han mostrado una ocupación romana muy anterior, y un precoz interés por la explotación de sus recursos naturales, en especial los metales. El gobierno de Augusto supone por lo tanto, más que una fase pionera, el periodo fundamental en el proceso de urbanización y de vertebración política de estas comunidades pirenaicas.

Palabras clave: Pirineo. Augusto. Ceretanos. Iulia Livica. Oro. Derecho latino.

\section{Augustus and the Control of the Pyrenees' Territory}

\begin{abstract}
The occupation of the Pyrenean areas during the reign of Octavian-Augustus, especially after the defeat of the Ceretans in the year $39 \mathrm{BC}$, has been regarded as the starting point for the process of Romanization of these territories, often considered marginal. However, recent archaeological work in the eastern Pyrenees have shown a much earlier Roman occupation, and an early interest in the exploitation of their natural resources, especially metals. The government of Augustus represents not a pioneering phase, but the fundamental period in the process of urbanization and political structuring of these Pyrenean communities.
\end{abstract}

Key Words: Pyrenees. Augustus. Cerretani. Iulia Livica. Gold. Latin rights. 
Es Floro (4.12) quien nos indica cómo Augusto, para conseguir la pacificación de los pueblos montañeses del norte peninsular, hizo descender a los indígenas del refugio de sus montes y les obligó a vivir en el llano. Esta imagen coincide plenamente con la visión de otros autores antiguos, como Estrabón (Geogr. 3.3.8), quienes insisten en una Roma civilizadora, que hizo descender a los indígenas de las altas cumbres, de sus poblados encastillados, para establecerlos en el llano y enseñarles las artes de la agricultura y el comercio. La humanitas se asociaba así a la vida en ciudades, a las áreas bien comunicadas, alejándose del modelo montañés, bárbaro y aislado. Sin embargo, a pesar de esta visión simplificadora, Roma se interesó sin duda por las áreas montañosas, cuyos recursos mineros o forestales no pasaron desapercibidos a los ojos de la administración civil y militar romana. Augusto, como en tantos otros aspectos, tuvo un papel importante en este renovado interés por las zonas montañosas, y en especial por el área pirenaica.

\section{Los territorios pirenaicos y la conquista romana}

Los geógrafos griegos y romanos tenían un conocimiento del espacio peninsular algo confuso, puesto que si bien las áreas costeras eran bien conocidas por los periplos y las rutas de navegación de época clásica, la disposición de las tierras interiores era objeto de debate entre los propios autores. Así, la descripción de Iberia por parte de Estrabón, sin duda la mejor fuente geográfica antigua con la que contamos, muestra las dudas y las opiniones contradictorias que tuvo el autor del Ponto al recoger los datos de los geógrafos precedentes. No debemos olvidar que la geografía grecoromana no era una verdadera geografía física en el sentido actual del término, y aunque sin duda los grandes fenómenos físicos eran claves para entender el espacio peninsular - básicamente grandes cadenas montañosas y grandes valles fluviales- el elemento clave para entender el espacio antiguo era la dimensión étnica y política de sus pueblos, es decir, la ubicación de la diversas comunidades humanas en el espacio, y sus afinidades culturales. ${ }^{1}$ En este mapa étnico, el Pirineo era un espacio particular: para todos los autores antiguos -incluido Estrabón- el Pirineo era una cadena montañosa ubicada más bien en sentido norte-sur que este-oeste, y la cornisa Cantábrica formaba parte del mismo eje, por lo que los Pirineos alcanzaban casi el Occidente peninsular. Los montañeses, fueran ceretanos, aquitanos, vascones o astures, eran sus pobladores, y sus características culturales eran similares al oponerse básicamente a las de sus vecinos en el llano, en una oposición étnica y geográfica bien presente en la geografía clásica.

Un segundo elemento confería al Pirineo un carácter especial: su carácter de límite territorial entre las provincias galas y las Hispanias lo convirtió en un límite político y cultural a los ojos romanos. Sin embargo, esta función de límite apareció con la propia conquista romana y la división provincial, puesto que en épocas anteriores, lejos de ser un límite o barrera, los Pirineos fueron una verdadera plataforma

1 Cruz Andreotti 2002. 
de contacto entre grupos culturales y étnicos diversos. ${ }^{2}$ Quizás de nuevo el ejemplo más paradigmático es el propio Estrabón, quién consideró a los Pirineos como un límite cultural entre galos e íberos, aunque esta definición se refería exclusivamente a una diferenciación administrativa, puesto que sabemos perfectamente que había comunidades culturalmente ibéricas en el área meridional de la Galia (con un límite establecido tradicionalmente en el río Herault), o pueblos de cultura vasco-aquitana tanto al sur como al norte de los Pirineos Occidentales. La información más antigua con la que contaban estos geógrafos era de origen griego, lo que se corresponde bien con el propio nombre griego de la cordillera -originada en el término griego Pyros, fuego- y con las tradiciones míticas griegas vinculadas a Hércules y a su mítico viaje a la Península. Más o menos legendarios, estos mitos recogen un conocimiento antiguo de sus recursos, especialmente los mineros, y una frecuentación de sus límites que se corresponden bien con la presencia griega en el Golfo de León.

\section{El territorio de los ceretanos}

Por lo que respecta al mapa étnico del Pirineo, poco es lo que sabemos antes de la llegada de los romanos y, básicamente, se debe a las fuentes que describen el paso de Aníbal por los Pirineos en el 218 a.C., en el inicio de la segunda guerra púnica.

El área más occidental parece estar poblada por los vascones, un pueblo que aparece en Silio Itálico (Punica 3.357) vinculado al ejército de Aníbal -quizás como tropas mercenarias- mientras que el área más oriental aparece poblado por un gran grupo étnico, los ceretanos o cerretanos, también aliados de Aníbal. Algunos otros grupos menores, como los Airenosios y Andonsinos, son mencionados por Polibio (3.35.2) al referirse a algunos combates que tuvo con ellos Aníbal. Por su nombre, hemos ubicado tradicionalmente a los Airenosios en el Valle de Arán y a los Andosinos en el valle de Andorra, pero nada sabemos de ellos a nivel arqueológico, y probablemente deben ser considerados grupos menores de un grupo étnico amplio que posiblemente sean los mismos ceretanos. ${ }^{3}$ Estos ceretanos, también por homonimia, se han ubicado en la actual comarca pirenaica de la Cerdaña, y son sin duda el pueblo mejor conocido tanto por las fuentes como por los recientes trabajos arqueológicos.

\section{El poblamiento ceretano}

Recientemente, nuevos trabajos desarrollados en la comarca de la Cerdaña han permitido conocer la evolución de estas sociedades a partir del s. IV-III a.C., mucho antes de la llegada del mundo romano. Así, es a principios del s. IV a.C. cuando se data la fundación de un nuevo yacimiento en la comarca, el Castellot de Bolvir (Cerdaña), que por primera vez responde al modelo del oppidum, es decir, un establecimiento amurallado, planificado, y que concentra en su interior actividades de producción,

2 Beltrán-Pina 1994; Olesti-Mercadal 2005, 2010.

3 Rico 1997. 
residencia y almacenamiento, con clara vocación de control territorial. ${ }^{4}$ Es bien sabido que el oppidum caracteriza un modelo territorial y político bien documentado en las áreas costeras y prelitorales, por ejemplo las sociedades ibéricas, pero hasta el momento no había sido documentado en las áreas pirenaicas.

El Castellot de Bolvir (1140 m.s.n.m.) ocupa una superficie de 0,6 Ha., de las cuáles solo hemos excavado hasta el momento un $20 \%$, y ocupa una pequeña elevación - una antigua morrena glaciar- sobre el curso del río Segre. La cronología fundacional de la muralla, datada por $\mathrm{C} 14$, nos lleva a principios del s. IV a.C., lo que es también coherente con los materiales más antiguos documentados. En el interior, los espacios domésticos estaban organizados según un modelo urbanístico sencillo, bien documentado tanto en el mundo del BF como ibérico: las casas compartían las paredes medianeras, y su muro trasero era la propia muralla o muro perimetral, lo que implicaba un programa de construcción unitario y contemporáneo. Conocemos en la actualidad 17 unidades domésticas dispuestas en batería y radialmente a lo largo de la muralla perimetral excavada, lo que permite calcular un total de 40 si proyectásemos estos resultados al conjunto del yacimiento. Ello podría darnos un mínimo de 150200 habitantes para el oppidum -números coherentes para una superficie total de 0,6 $\mathrm{Ha}$ - aunque debemos tener en cuenta la posible existencia de casas en el espacio central, aún no excavado, que podrían quizás llevarnos a un total de unos 250 habitantes.

Los primeros estudios de restos vegetales llevados a cabo en el Castellot confirman los datos procedentes de otros yacimientos ceretanos, como St. Feliu de Llo, ${ }^{5}$ donde se ha confirmado la existencia del cultivo de cereales como el trigo y la cebada, combinada con especies leguminosas, como los guisantes. La cebada es un cereal bien adaptado a las tierras altas, y muy bien documentado en el mundo ibérico. En el Castellot se ha documentado también el mijo, un cereal de ciclo corto, que podría ser muy conveniente en un modelo trashumante vertical, dada su escasa necesidad de agua -no olvidemos que el llano de la Cerdaña presenta una baja pluviosidad, compensada en la actualidad por complejos sistemas de riego- y su rápido crecimiento, compatible con la necesidad de pastos en el llano. También la existencia de silos en los espacios comunitarios, y el número elevado de molinos -tanto de vaivén como rotatorios- nos habla de una notable producción agrícola.

Por lo que respecta a la ganadería, los estudios de fauna han documentado la presencia de bóvidos, ovi-cápridos y suidos, por este orden de importancia. Los bóvidos presentan una edad de sacrificio superior a los 3 años, el momento de estabilización de su peso, por lo que no se aprovecharon para la obtención de carne, pues ese sería el momento óptimo para su sacrificio. La supervivencia de todos los ejemplares más allá de los 3 años, con incluso ejemplares de más de 6 años, nos indica que los bóvidos fueron utilizados especialmente para la tracción y la reproducción, puesto que tampoco la producción de leche de vaca fue habitual en la antigüedad. Se trata de bóvidos de pequeña talla, y su porcentaje tan elevado -también documentado en

4 Olesti ET ALII 2010 ; MoRera ET ALII 2012 y 2014.

5 Rendu 2003; Olesti-Mercadal 2005. 
St. Feliu de Llo- es propio del mundo pre-romano pirenaico, y debe vincularse a la existencia de pastos abundantes y condiciones climáticas favorables. ${ }^{6}$

Los ovi-cápridos, la segunda especie más documentada en el Castellot, es la más habitual en el mundo ibérico del NE, y su uso tanto para la producción de lana, leche y carne la convierten en una especie de gran interés económico. Por lo que respecta a los suidos, el hallazgo de un ejemplar neonato, la documentación de algunos ejemplares subadultos y uno adulto, permite confirmar la crianza de los suidos en el propio poblado, y su probable explotación para la obtención de carne. Ello coincidiría bien con los datos de Estrabón (3.4.11) que considera a los ceretanos grandes productores de pernae, jamones curados con sal, que en época imperial se exportaron a Italia. Finalmente, ya en esta fase se documenta la presencia de équidos, un tipo de animal que a pesar de su interés cárnico y para el transporte, puede también vincularse en el contexto ibérico a la existencia de grupos sociales privilegiados.

Este modelo ganadero transhumante, con preponderancia de los bóvidos, ha sido también documentado en St. Feliu de Llo, y especialmente en Enveig. ${ }^{7}$ En Llo, los restos faunísticos aportan una cabaña ramadera muy similar a la del Castellot, aunque la ubicación del yacimiento a mayor altura (a casi $1.700 \mathrm{~m}$ ) permite ubicarlo ya a medio camino de las zonas de pasto de verano de Eina y el Puigmal. Más significativo es el yacimiento de l'Orri d'en Corbill (Enveig), ubicado a unos $1950 \mathrm{~m}$ de altura. Consiste en una pequeña cabaña de pastor de unos $7 \mathrm{~m}^{2}$, construida aprovechando algunos bloques locales, completados con un sencillo paramento de piedra. Se localizaron algunos escasos fragmentos de cerámica a mano local, pero una cronología C14 del hogar, mediados del s. IV a.C., no deja lugar a dudas sobre la filiación ceretana de la cabaña. Lo interesante de este yacimiento, que no debió ser el único, es su ubicación en el trayecto de una cañada que se dirige hacia las áreas de pastos de verano del Carlit, lo que confirmaría la existencia de este modelo transhumante vertical. Se trataría, pues, de pequeñas cabañas de pastor, con una mínima cultura material (no olvidemos que los pastores llevan consigo los utensilios necesarios, lo más livianos y resistentes posibles), y que básicamente consistían en un reducido espacio protegido de las inclemencias, calentado por un hogar central, imprescindible en estas elevadas cotas. La estacionalidad de la cabaña parece clara, puesto que con las primeras nevadas el lugar debería abandonarse, y coincidiría con el ciclo ganadero y el descenso de los rebaños hacia el llano.

Este llano ceretano no estaba tan sólo controlado por el oppidum del Castellot, que hoy por hoy es el mejor conocido. A lo largo del río Segre, el verdadero eje vertebrador de la Cerdaña, se documentan al menos 3 yacimientos más que pueden relacionarse con el modelo del oppidum. En la cota más alta, controlando el nacimiento del río, el poblado de St. Feliu de Llo, al que ya nos hemos referido. Unos $7 \mathrm{~km}$ río abajo se encuentra Llívia, el futuro solar de la ciudad romana de Iulia Livica. Aquí, en el Puig del Castell, una colina que controla el paso de la via medieval transpirenaica y el paso del Segre, se hallaron materiales del Bronze Final - Hierro, y en cotas más bajas, por debajo de las estructuras romanas de Iulia Livica, se hallaron silos y materiales

6 Colominas 2013.

7 ReNDU 2003. 
correspondientes a un núcleo ceretano mal conocido. ${ }^{8}$ No es posible afirmar que se trate de un oppidum -que en cualquier caso debería encontrarse en lo alto de la colina, hoy ocupada por la imponente fortificación del castillo medieval y moderno- pero el hallazgo de materiales como algunos fragmentos de copa ática, y de materiales ceretanos prácticamente en todas las áreas urbanas del pueblo, nos habla de un yacimiento ceretano de entidad. Que en este lugar se ubicara la futura capital romana de los cerretani parece también un indicio interesante.

Unos $10 \mathrm{~km}$ río abajo se halla el oppidum del Castellot, y unos $9 \mathrm{~km}$ más allá se encuentra el yacimiento del Turó de Baltarga (Bellver de Cerdaña), de nuevo ubicado en una elevación estratégica, que cierra la llamada "plana cerdana" y controla el paso fluvial y terrestre hacia las tierras bajas. Conocemos algunos muros y restos de habitaciones ortogonales de esta cronología, así como agujeros de poste que nos indican la existencia de un techado de material perecedero, con lo que el lugar podría definirse como un hábitat encastillado, con una función de control visual y territorial. ${ }^{9}$ La localización por parte de aficionados de diversas dracmas de imitación del s. III a.C. -así como una imitación gala de dracma emporitana de iconografía cartaginesa localizada en nuestras excavaciones-, confirma la ocupación del lugar durante el s. III a.C. Se trata de un conjunto notable de dracmas, que reflejan por un lado la vitalidad de esta vía transpirenaica, y quizás también la exigencia de derechos de paso por parte de los ceretanos, reflejado en episodios posteriores.

En resumen, las pautas territoriales ceretanas muestran un sistema territorial coherente, muy alejado del poblamiento disperso y en cabañas que suponíamos tan sólo hace algunos años, y que por primera vez parece corresponderse a la descripción que Silio Itálico (Pun. 3.357) hizo de los ceretanos: Cerretani, quodam Tyrynthio Castra, es decir, los ceretanos, antiguos soldados de Tirinto, o mejor, antiguos pobladores de fortines tirintios. Sea en uno o otro sentido, es posible suponer que Silio Itálico se refería a las potentes defensas de los ceretanos, lo que parece coherente con la serie de fortificaciones ubicadas en el curso del río Segre que hemos identificado.

\section{¿Una comunidad ibérica?}

Las características de este poblamiento ceretano nos llevan lógicamente a la cuestión de la filiación cultural de este pueblo. Los autores que recogen las fuentes literarias más antiguas (por ejemplo Avieno, O.M. 549-552, o Esteban de Bizancio, Ethn.THA $I I B, 931)$ reflejan claramente una distinción entre los ceretanos y las comunidades ibéricas, mientras que en cambio los autores posteriores, como Estrabón (3.4.11), los consideran un grupo ibérico más.

\footnotetext{
8 Olesti-Mercadal 2010.
}

9 Oller-Morera 2013. 
Los resultados arqueológicos en el Castellot y los otros yacimientos, nos han mostrado que la llegada a la Cerdaña no solo de algunos materiales ibéricos ${ }^{10}$ sino también de formas de poblamiento y control territorial propias de las comunidades costeras, debe retrasarse al s. IV, con lo que no se trataría de una iberización tardía, como se pensaba, sino de un proceso de génesis de una sociedad proto-estatal más antiguo de lo que suponíamos. La construcción de un verdadero oppidum debe vincularse a una voluntad de control territorial y social que solo puede explicarse en el marco de un desarrollo político y social propio de comunidades proto-urbanas o urbanas. Esta complejidad se ha visto también confirmada por la existencia en la Cerdaña de un corpus de inscripciones rupestres ibéricas, sin paralelo en el mundo ibérico peninsular. Se trata de un conjunto de 35 rocas, con más de 140 textos y 1400 signos ibéricos, ubicadas normalmente cerca del llano, a media pendiente, y no muy alejadas de hábitats ceretanos documentados. ${ }^{11}$

Este corpus, sorprendente para un territorio que hasta hace pocos años considerábamos poco iberizado, demuestra la existencia de poblaciones que tenían el hábito de la escritura, que lo hacían utilizando el alfabeto ibérico, y cuyos antropónimos son en su gran mayoría de filiación ibérica. El uso tanto de la escritura dual (más antigua) como la no dual (ya en contacto con Roma) refleja la antigüedad de estos textos, coincidiendo plenamente con las cronologías iniciales del Castellot y Llívia. La reciente identificación de diversos abecedarios ${ }^{12}$ muestra el carácter votivo de, al menos, una parte de estos textos, con paralelos claros en otras áreas ibéricas levantinas.

De todo ello se desprende que las comunidades ceretanas, lejos de ser un tradicional grupo montañés, alejado de fenómenos como la difusión del urbanismo o de la escritura, tuvo desde el s. IV a.C. un desarrollo social y cultural complejo, paralelizable al de otras áreas ibéricas del NE, y que si bien muestra diferencias notables con las zonas de costa y prelitoral (en especial la práctica ausencia de cerámicas a torno, o el peso de la ganadería), parece responder en lo fundamental a lo que hoy en día consideramos como comunidades ibéricas. Ello es importante, puesto que cuando se produjo el contacto con el mundo púnico y romano, los ceretanos sin duda formaban parte de un mosaico étnico y político bien establecido.

\section{Un territorio en los márgenes de la provincia Citerior}

El paso de Aníbal por los Pirineos, bien documentado en Livio y Polibio, supuso el primer contacto de los ceretanos con las potencias Mediterráneas del momento. Según Polibio (3.35) Aníbal, con 90.000 infantes y 12.000 jinetes, cruzó el Ebro y sometió a los pueblos de los ilergetes, bargusios, y poco después, como ya vimos, a

10 Se trata básicamente de cerámica ibérica a torno, procedente tanto de las áreas costeras como del interior, pero en unos porcentajes tan reducidos (a penas un 5\%), que no puede dudarse de su origen foráneo. Contrasta este porcentaje con el $95 \%$ de cerámica a mano, de formas recurrentes, que nos hablan de una identidad ceretana clara a nivel de cultura material.

11 Campmajo 2012; Ferrer 2015.

12 FERRER, en prensa. 
los airenosios y andosinos. En esta operación, sigue Polibio, el comandante púnico debió tomar por la fuerza algunas ciudades, perdiendo algunas tropas. Controlado el territorio, Aníbal dejó al control del territorio entre el Ebro y el Pirineo a Hannón, vigilando especialmente a los Bargusi, un pueblo amigo de Roma.

Livio (21.23), en cambio, nos describe una situación algo diferente, pues indica cómo Aníbal cruzó el Ebro por tres puntos, y sometió a ilergetes, bargusios, ausetanos y la Lacetania, dejando a Hannón al frente de esta zona y siguiendo hacia la Galia con sus 37 elefantes (que lógicamente debieron cruzar el Pirineo, una buena sorpresa para los pueblos montañeses...). Las tropas de Aníbal llegaron así a Iliberris, actual Elna, en el curso del río Tet, lo que posiblemente indicaría un paso de las tropas púnicas por diversos puntos.

Finalmente, el texto de Silio Itálico, mencionando la colaboración de ceretanos y vascones con el ejército de Aníbal, confirma los datos de Polibio, y el paso interior de las tropas púnicas también (quizás no exclusivamente) por el paso de la Cerdaña.

De los datos de las fuentes se extraen algunas interesantes conclusiones. Por un lado, como ha sido destacado por muchos autores, Aníbal evitó el paso por la costa, posiblemente un territorio poco afín a sus intereses. En segundo lugar, un paso interior privilegiado sería el del curso del río Segre (cerca del cual podemos ubicar a los ilergetes, andosinos y ceretanos) y el descenso por el Tech. Posiblemente otro grupo pudo avanzar por el Prepirineo (Lacetania, bargusios, y a través del Ripollés hacia Camprodón) y descender por el río Tet. Los dos autores coinciden en el papel de los Bargusioi, posiblemente los Berguistani, un pueblo pre-pirenaico con un papel estratégico en el panorama indígena, a juzgar por un poco valorado texto de Livio (21.19) que nos indica el envío de una embajada romana a su encuentro antes de la llegada de los Escipiones en el 218 a.C. para poder contar con su ayuda contra los púnicos.

Estos Berguistani-Bargusioi, muy mal identificados arqueológicamente, podrían encontrarse en la actual comarca del Berguedà, y extenderse quizás hacia el vecino Solsonés. Su posterior intervención en las campañas de Catón confirma, sin duda, su papel clave en el control de las áreas pre-pirenaicas. Finalmente, es interesante destacar el papel pro-púnico del mundo ceretano, una alianza necesaria para Aníbal si quería evitar el conflicto con un pueblo notablemente fortificado -los Tyrynthia castra de Silio Itálico- y que controlaba con algunos fortines como mínimo el curso más alto del río Segre. Las luchas con airenosios y andosinos debieron ser complicadas, y el general Cartaginés prefirió pactar con los ceretanos y mantener el control sobre los estratégicos bargusios para garantizarse un paso de los Pirineos lo más rápido posible.

Para los romanos en cambio, la cuestión fue muy diferente. Desembarcados en Emporion, una ciudad estratégicamente ubicada al pie de la cordillera pirenaica, los cursos de los ríos Fluvià, procedente de la Garrotxa, y Ter, procedente del Ripollés, permitían un contacto relativamente fácil con los valles pirenaicos más orientales. No tenemos indicio alguno de contactos con los ceretanos, por lo que parece convincente la división de la cordillera entre una zona interior más pro-púnica, y otra costera más pro-romana. Sin embargo, esta situación no duró mucho tiempo. La rebelión indígena del 197 a.C. provocó la intervención del cónsul Catón en la Citerior, quién emprendió 
diversas expediciones contra los pueblos pre-pirenaicos: los Lacetani y los Berguistani, precisamente los antiguos y fieles aliados romanos. A pesar de algunos problemas en las fuentes, Livio nos describe bien la existencia de una comunidad Lacetana, organizada en torno a un oppidum longum, que tomó con facilidad. Más complejas son las pautas de los Berguistani, establecidos en castella, siete de los cuales se rebelaron contra Catón (Livio, 34.16). Tras un primer sometimiento, debió atacar luego su capital, el Bergium castrum (Livio, 34.21), pactando con su princeps Berguistani una rendición secreta y la entrega de los rebeldes.

De estos datos se desprende que, a semejanza de los ceretanos, también estos pueblos prepirenaicos tenían un sistema de control territorial diversificado, que incluso en el caso de los berguistanos se refleja en una terminología precisa-castella, castrum - indicativa de unos sistemas defensivos complejos, pero que no llegaron a alcanzar propiamente las formas urbanas, y en este sentido similares a la misma mención de Silio a los castra ceretanos. Si las campañas de Catón llegaron a alcanzar o no los territorios ceretanos, es algo que las fuentes no nos indican. Su ausencia en los textos parece indicar que no, pero también es cierto que Catón alcanzó pactos con la mayor parte de pueblos cis Hiberum, por lo que bien podrían ser los ceretanos uno de los pueblos que quedaron vinculado a Roma a partir de pactos de rendición, como fue el caso de los mismos Ilergetes.

Finalmente, nuestra información sobre la expedición de Catón termina con una referencia al establecimiento de tributos sobre las minas de hierro y plata: pacata provincia vectigalia magna instituit ex ferraris argentariisque (Livio, 34.21.7), lo que confirió grandes riquezas a la provincia. El texto de Livio indica claramente la imposición de unas primeras tasas a las zonas mineras controladas por Roma, y que seguramente debían incumbir a aquellos publicani o privados que decidieron arrendar estas minas al estado. Por ello, es frecuente vincular estos vectigalia a las explotaciones mineras de zonas como Cartagena, lo que parece muy posible, pero deberíamos tener también en cuenta otra fuente menos citada, y sin embargo también muy explícita, Aulo Gelio (Noches áticas 2.22.28), quién recoge la mención del propio Catón a las minas cis Hiberum. Se trata de una referencia a las regiones al norte del Ebro, "donde hay minas de hierro, hermosísimas minas de plata, y un gran monte de sal pura; tanto cuanto se extrae, tanto crece". La referencia a un monte de sal pura no puede sino referirse a la montaña de sal de Cardona (precisamente en el Solsonés, es decir, cerca del territorio berguistano), y tanto esta referencia a la sal, como a las minas de hierro y plata, nos llevan a pensar en áreas circunpirenaicas, de cuya riqueza en metales nos hablan, como vimos, los autores antiguos. Es cierto que también en otras áreas de Cataluña conocemos minas de plata y hierro -como por ejemplo en la comarca del Priorat-, pero nos parece como mínimo interesante recordar también el contexto pirenaico de buena parte de los sucesos descritos por Catón, y no descartar por ello la existencia de minas en esta región. 


\section{La intervención en el Pirineo axial. Roma y los ceretanos}

Tras la intervención catoniana, y las referencias a las minas del NE, las áreas pirenaicas desaparecen de las fuentes literarias, y no será hasta los episodios de las guerras civiles cuando esta zona volverá a ser de interés para los autores antiguos.

Por ello, se ha considerado que las tierras altas pirenaicas quedaron fuera del control romano, y se convirtieron en un límite septentrional del territorio controlado a lo largo del Valle del Ebro y del NE, una especie de tierra de nadie entre los galos del sur de Francia y la zona hispana romanizada. Tan sólo con la conquista del sur de Francia por Domicio Ahenobarbo a partir del 125 a.C., los Pirineos volverían a ser un territorio estratégico para el dominio romano.

Sin embargo, los datos arqueológicos contradicen esta visión, demostrando el carácter estratégico del Pirineo oriental antes del 125 a.C. No es posible afirmar que fueran áreas ya controladas desde época de Catón, pero en cualquier caso la presencia romana desde la primera mitad del s. II a.C. nos indica un probable contacto estable con la administración romana, y quizás incluso una política de pactos similar a la que se estableció con otras zonas de la periferia provincial. Los datos arqueológicos son en este sentido muy sugerentes. Así, en el caso del Castellot, se documenta en torno al año 200 a.C. un fenómeno de amortización de los silos comunitarios, fenómeno ampliamente documentado en el mundo ibérico catalán, y que coincide con los episodios militares vinculados tanto a la guerra púnica como especialmente a las actividades del cónsul Catón. ${ }^{13}$ El Castellot, pues, muestra una evolución similar a otros oppida costeros, con una lenta recuperación de la capacidad agrícola a lo largo del s. II a.C., especialmente en la segunda mitad. Esta inflexión en la producción agrícola, sin embargo, no se vincula a ningún despoblamiento, puesto que el Castellot muestra claros indicios de continuidad a lo largo de la primera mitad del s. II a.C., con incluso algunas pequeñas remodelaciones urbanísticas.

La situación se transformó completamente a mediados del s. II a.C. En este momento el oppidum sufrió una remodelación urbanística completa, que afectó la totalidad de las estructuras ceretanas: se construyó una nueva puerta en la muralla principal del poblado, se reorganizó completamente la red de casas, y se edificaron espacios productivos especializados, sin paralelos en la fase anterior. ${ }^{14}$ La filiación de muchos de estos cambios parece claramente vinculada a una presencia romana en el lugar-probablemente militar-, constituyendo una guarnición o praesidia, pero sin duda el oppidum continuó siendo un centro mayoritariamente ocupado por población indígena, como lo indica la inmensa preponderancia de las cerámicas a mano de tradición local.

Todas las nuevas estructuras se construyeron utilizando un aparejo diferente, lajas de pizarra, y presentan unas dimensiones uniformes, vinculadas al uso del pie romano, de 29,6 cm, y su múltiple de 10, la pertica.${ }^{15}$ Así por ejemplo se construyó una

13 Olesti 2000 y 2014.

14 Morera ET ALII, 2012, 2014.

15 Se trata especialmente del uso de la decempeda o pertica, es decir, una vara de diez pies romanos $(2,95$ m) que formaba parte del equipo básico de los mensores, ingenieros de carácter militar. 
puerta monumental de $2.96 \mathrm{~m}$ de anchura, flanqueada por dos torres quadrangulares, que presentan unas medidas externas de $5,9 \mathrm{~m}$ y un espacio interno de $2,96 \mathrm{~m}$, y un cuerpo de guardia adosado de $9 \mathrm{~m}$ organizado en casamatas, todo ello en un proyecto claramente unitario que confiere al oppidum una entrada imponente. Los paralelos de esta puerta protegida por dos torres laterales deben buscarse en yacimientos de clara filiación romana y cronología similar, como Olérdola o Emporion, y muy poco tienen que ver con la tradicional poliorcética ibérica. También múltiples de la pertica son las medidas que documentamos en los nuevos edificios que se superponen a las antiguas casas ceretanas, y que tanto a nivel de técnica constructiva (grandes muros en pizarra, de 0,80 o $0.90 \mathrm{~m}$ de grosor) como de superficie (algunos de más de $150 \mathrm{~m}^{2}$ ) tienen muy poco que ver con los espacios domésticos anteriores.

El caso más sorprendente es sin embargo el edificio exento IV, situado en la parte central del asentamiento. Se construyó totalmente ex novo en una zona de antiguas construcciones ceretanas que fueron totalmente desmanteladas y arrasadas. Corresponde a un módulo de tres habitaciones dispuestas en batería, comunicadas entre sí, dedicadas todas ellas a las actividades metalúrgicas. En la central se ha documentado claramente la producción del hierro, pero en las laterales, presididas cada una por un hogar de arcilla decorado, se ha documentado una actividad polimetalúrgica, con producción de bronce, latón, plomo, plata y oro. Además, se documentó la presencia de cinabrio, un metal muy valorado en época romana, y cuya producción en la península en época romana solo se ha documentado en Sisapo (Almadén). ${ }^{16}$ Los restos de escorias de plomo, la presencia de azurita (cobre), y la gran presencia de piezas de metal -como una espátula de bronce de tipo quirúrgico decorada con una cabeza de lobo-, permiten pensar en el reciclaje de algunos objetos metálicos. Sin embargo, el hallazgo reciente de una viruta de plata y de una partícula de oro trabajado nos habla también de un taller de orfebrería, de un elevado nivel tecnológico. ${ }^{17}$ Hay que tener en cuenta que la presencia de latón y de cinabrio (que podría utilizarse para efectuar amalgamas y dorados) no son muy frecuentes en estas cronologías.

El taller permite casi con toda seguridad plantear la presencia de un contingente romano en el lugar -en esta cronología y contexto, de probable filiación militar-, puesto que no parece que las comunidades ceretanas tuvieran acceso a esta tecnología. Se trataría de un pequeño grupo de soldados -y auxilia- ubicados en el oppidum, destacados como tropas de control de la vía transpirenaica y como apoyo logístico a las tropas ubicadas a lo largo de la región. Su función como punto de reclutamiento de tropas indígenas tampoco puede descartarse, y sería claramente compatible con el praesidium.

Por lo que respecta al oro, la cuestión es polémica, puesto que, como veremos, en la Cerdaña y valle del Segre existen importantes depósitos de oro aluvial, de probable explotación en época antigua. ${ }^{18}$ Además, en una de las habitaciones remodeladas se halló un pendiente de oro naviforme de buena factura, de mediados del s. II a.C. No

16 Se trata de resultados obtenidos en colaboración con el equipo dirigido por el Prof. Ignacio Montero (MicroLab, CSIC) a quien agradecemos su implicación en este proyecto.

17 Montero ET ALII, en prensa.

18 Morera et ali 2012, Olesti ET ALII, en prensa. 
podemos asegurar que el oro del taller ni de la joya proceda de la comarca, puesto que no existen elementos traza para confirmarlo, pero tampoco es muy convincente la actuación de un orfebre en un yacimiento indígena relativamente modesto, y en el marco de actuación de una probable guarnición militar.

Este mismo contexto militar ha sido también documentado en el cercano yacimiento del Turó de Baltarga. ${ }^{19}$ Sobre el yacimiento ceretano se erige también a mediados del s. II a.C. un conjunto de edificios articulados en torno a una potente torre cuadrangular, de unos $5 \mathrm{~m}$ de lado y muros de $1,2 \mathrm{~m}$ de grosor, construida también con aparejo de losas de pizarra. El material cerámico, con un $80 \%$ de cerámica a mano, recuerda de nuevo el contexto indígena del Castellot, pero también aquí han aparecido algunos materiales sorprendentes, altamente significativos. Por un lado, ha aparecido un pequeño clavo de caliga, la sandalia típica de los soldados romanos, muy característica de los contextos militares. Más sorprendente aún ha sido el hallazgo de un anillo de hierro con su parte superior dorada en oro y plata, que corresponde a un sello, un anulus. Se trata de una pieza excepcional, tipológicamente similar a otros anillos de hierro hallados en contextos bélicos de época republicana (como por ejemplo en Baecula, en el escenario de la famosa batalla del 206 a.C.), pero que presenta una cara superior dorada en oro y plata, que pese a su deterioro muestra claramente su función de sello. La presencia de un sello dorado a partir de una amalgama de oro y plata puede relacionarse con las tropas romanas. En un pasaje de Apiano (De reb. Pun., 105) referente a la tercera guerra púnica, por lo tanto en un contexto cronológico similar, se menciona explícitamente cómo los soldados romanos llevaban frecuentemente anillos de hierro, mientras que los tribunos llevaban en cambio anillos de oro, como sería el caso que nos ocupa. A nivel cerámico, la presencia de ánforas greco-itálicas e itálicas brindisinas, entre otras, también nos dibuja un contexto de aprovisionamiento típicamente militar.

En resumen, y contrastando con unas fuentes literarias que reflejan un Pirineo alejado del control romano, los datos arqueológicos nos indican que ya a mediados del s. II a.C. el territorio ceretano se encontraba bajo el control efectivo de Roma, desplegado en guarniciones ubicadas en los centros principales de poblamiento indígenas, y en una aparente convivencia pacífica con las poblaciones locales. Las guarniciones están bien documentadas en el caso del Castellot y el Turó de Baltarga, y es posible suponer su existencia en los dos otros núcleos de población documentados en la comarca, Llívia y St. Feliu de Llo, donde los materiales de s. II-I a.C. son muy abundantes.

\section{Los Pirineos y las guerras civiles}

Deberemos esperar a principios de s. I a.C. para que esta presencia romana, documentada a través de la arqueología, se vea también reflejada en las fuentes literarias.

19 Oller-Morera 2013. 
Un primer dato nos lo ofrece el conocido bronce de Ascoli del año 89 a.C. (CIL I, 709). En el año 91 a.C. los aliados itálicos de Roma se rebelaron contra la metrópoli, cansados de esperar una integración política y jurídica que nunca llegaba. Ante la falta de tropas auxiliares, los comandantes romanos se vieron obligados a reclutar tropas entre los pueblos provinciales más favorables, entre ellos algunas comunidades del valle del Ebro (Apiano, $B C$ 1.89). En el año 89 a.C., por sus méritos en combate en Ascoli, un grupo de 30 jinetes hispanos, la Turma Salluitana, recibieron la ciudadanía romana como premio. Se trata por lo tanto de caballeros hispanos reclutados como auxilia, cuya procedencia está bien atestiguada en el documento: Salluie (Zaragoza), Ilerdenses (Ilerda-Lérida), los Segiensis (Ejea de los Caballeros), los Libenses (probablemente la Iulia Livica de los ceretanos), los Suconsenses (ciudad Ilergete en Ptolomeo, 2.6.67), los Bagariensis, los Illversensis, los Begensis, los Ennegensis, y los (-)licenses. Todos estos núcleos, por lo tanto, fueron puntos donde se reclutaron tropas auxiliares, vinculados posiblemente a la logística militar romana.

Aunque para algunos autores los Libenses podrían ser originarios de la Libia Berona (actual Herramellurri, en la Rioja), los antropónimos ibéricos de los dos jinetes mencionados en el bronce no dejan lugar a dudas sobre su filiación étnica, por lo que dificilmente podrían ubicarse en el territorio berón, de filiación céltica. Descartada la Libia Berona, podría ser en la Libia ceretana donde se habrían reclutado estos dos jinetes. Estos datos son plenamente coherentes con los datos arqueológicos conocidos en Llívia. Así, por encima de los niveles ceretanos antes mencionados, es frecuente el hallazgo en Llívia de materiales del s. II-I a.C. en diversos puntos del solar de la ciudad, con incluso un conjunto de ocho silos excavados de esta cronología, lo que nos indica la existencia de algún tipo de establecimiento al pie del Puig del Castell, el cerro que estratégicamente controla el paso del Segre. Además, recientemente se ha localizado un grafito ibérico sobre cerámica campaniana de finales del s. II a.C., lo que confirmaría la presencia de la población ceretana en el núcleo. Además, si retomamos el bronce, veremos que a parte de los Libenses aparecen también los Ilerdenses, que nos marcarían la vinculación de estos pueblos a través del valle del Segre y, quizás, el desplazamiento de estas tropas auxiliares hacia Italia precisamente por esta vía transpirenaica. El reclutamiento de auxilia ceretanos, vinculados a su futura capital Libia, nos parece plenamente coherente con el contexto arqueológico de segunda mitad del s. II a.C. bien documentado en Baltarga y el Castellot.

La colaboración de los ceretanos con el ejército romano, voluntaria o no, tuvo fuertes implicaciones para esta comunidad, especialmente cuando pocos años después estallaron las guerras civiles, que convirtieron a estos territorios en un teatro de operaciones de primera magnitud. El primer gran episodio tuvo lugar con las guerras sertorianas. En el año 83 a.C., a punto de caer en manos de Sila, el popular Quinto Sertorio abandonó Italia para refugiarse en Hispania y conseguir su apoyo en la lucha contra los optimates. Plutarco (Sert. 6) nos describe su llegada a la provincia, asediado por fuertes tempestades en la montaña -en una referencia que parece clara al cruze de los Pirineos por un paso interior, no el costero-, y el pago que tuvo efectuar de derechos de paso, telos, a los indígenas, para poder cruzar la zona. La imagen parece reflejar unos pueblos no sometidos a Roma, pero no olvidemos que Sertorio y 
su séquito cruzaron los Pirineos prácticamente como fugitivos, lo que podría explicar el pago de estos telea. En cualquier caso, si el paso por la Cerdaña fue el escogido, el control que yacimientos como Castellot o Baltarga ejercían sobre la vía transpirenaica explicarían perfectamente el pago de derechos de paso.

En el año 81 a.C., Sertorio decidió fortificar los pasos pirenaicos para hacer frente a las tropas silanas que avanzan desde la Narbonense. Según nos indica Plutarco (Sert. 6), Livio Salinator, al frente de 6.000 infantes (una legión), ocupó los pasos elevados. Cayo Annio, enviado por Sila, debió detenerse al pie de los Pirineos ante la inutilidad del ataque, pero una traición le facilitó el camino: Calpurnio Lanario asesinó a Salinator, y rápidamente sus tropas abandonaron las alturas. Annio franqueó rápidamente los pasos, y las tropas sertorianas se retiraron hacia el sur. No sabemos con precisión dónde se produjeron estos hechos, pero en cualquier caso la fortificación de los pasos de Livio Salinator-que se hizo sin aparentes dificultades, a juzgar por el texto de Plutarco-implicaba un control previo de la zona, lo que coincide plenamente con la serie de praesidia bien documentadas en la Cerdaña.

Pero no terminan aquí nuestras fuentes. En el año 78 a.C., en plenas guerras sertorianas, Lucio Manlio, el procónsul de la Galia Narbonense, acudió en ayuda de las tropas senatoriales (César, BG 3.20.1, Orosio, Adv. Pag. 5.23.4). Partiendo de Narbo$n a$, con tres legiones y 1.500 jinetes, sabemos que fue atacado en las inmediaciones de Ilerda por las tropas de Hirtuleyo, un comandante sertoriano, y debió refugiarse en la ciudad perdiendo todos sus pertrechos. De allí, parece que regresó a su provincia a través del territorio aquitano. La ruta Narbona-Ilerda-Aquitania parece reflejar un teatro de operaciones muy cercano al área que nos ocupa, donde probablemente el control de los pasos pirenaicos fue clave en el desarrollo de los combates. En este sentido, no podemos olvidar que fue en Osca donde Sertorio estableció su capital política, por lo que las áreas prepirenaicas debieron de estar bajo su área de influencia, y tener un importante valor estratégico. Los optimates debieron esperar a la llegada de Cn. Pompeyo para recuperar su iniciativa, y a pesar de los problemas que tuvo el jóven general, acabó derrotando a las tropas sertorianas. ${ }^{20}$ El Pirineo jugó un papel importante en los combates, si tenemos en cuenta que Pompeyo se refugió en la zona vascona durante algún tiempo, y que posteriormente estableció guarniciones pompeyanas en Pompaelo y Lugdunum Convenarum (Sant Bertrand de Comenges, cerca del Valle de Arán). Tras la victoria, Pompeyo edificó un espectacular trofeo cerca del Pertús, en el paso más oriental de la cordillera. Además, sabemos por una referencia explícita de Cicerón (Pro Fonteio 7) que el pretor de la Narbonense, M. Fonteyo, se encargó de reparar y mejorar las vias de la provincia, en especial la Via Domitia, en lo que parece un despliegue de infraestructuras en la zona pirenaica.

Tras las actuaciones de Pompeyo, los territorios pirenaicos volvieron a desaparecer de las fuentes literarias, pero no por mucho tiempo. Cuando en el año 49 a.C. se iniciaron los combates entre Cn. Pompeyo y Julio César, los legados hispanos de Pompeyo decidieron cerrar el acceso a la Península presentando una primera línea de defensa en los pasos pirenaicos, y una segunda en Ilerda, repitiéndose casi exacta-

20 Amela 2002. 
mente la misma situación del año 81 a.C. Es el propio Julio César $(B C 1.37)$ quién indica cómo $L$. Afranius, uno de los legados pompeyanos en Citerior, hizo fortificar los pasos pirenaicos con el establecimiento de diversas guarniciones, praesidia. Sin embargo, su capacidad defensiva fue limitada: Cayo Fabio, legado de César, tomó tres legiones que estaban acuerteladas en Narbona y rápidamente se dirigió a los pasos pirenaicos, expulsando rápidamente a las guarniciones pompeyanas. Fabio se dirigió rápidamente hacia Ilerda, donde le esperaban el grueso de las tropas pompeyanas, por lo que es muy probable que siguiera la ruta Narbona-Ilerda cruzando precisamente la Cerdaña. Unos días después le siguió el propio Julio César, que llegó a Ilerda con una guardia de 900 jinetes procedente de la Galia. Entre las tropas cesarianas eran numerosos los galos, pero también algunos montañeses de áreas cercanas, lo que podría incluir sin duda algunas comunidades pirenaicas (Cesar, $B C$ 1.39.1).

Como sabemos, a partir de ese momento la lucha se desarrolló en torno a la ciudad de Ilerda, y el juego de alianzas entre los dos bandos buscando la colaboración de las civitates indígenas vecinas fue clave para el desarrollo de la batalla. César supo granjearse mejor el apoyo de los indígenas, y al final decantó la batalla a su favor. Sabemos que como agradecimiento a su colaboración, César promovió numerosos beneficia a sus aliados, entre ellos los Ilergavones, Ausetani y Iacetani-dos de ellos prepirenaicos-, y es posible que de este momento date la promoción a colonia romana de Tarraco, y probablemente también el derecho latino de los ceretanos, documentado por Plinio. Ello implicaría que estos pueblos del NE, y en especial los peripirenaicos, se sumaron a su bando, y que le dieron un importante apoyo militar y/o logístico en el transcurso de la batalla. Los Pirineos, pues, no habían sido un territorio tan marginal y excéntrico como se pensaba, sino que una parte de los combates de las guerras civiles se produjeron en su área de influencia, y sin duda tuvieron un carácter estratégico.

\section{Hacia un nuevo modelo territorial: Octavio/Augusto y el dominio del Pirineo}

Este periodo de integración no estuvo ausente de contradicciones y problemas. La integración social y económica de estos territorios a raíz de las guerras civiles, que situó a las áreas pirenaicas en las redes viarias comerciales y de aprovisionamiento militar, pudo haber supuesto un teórico periodo de prosperidad para las comunidades ceretanos, que debería plasmarse -como en otras áreas- en la eclosión final del fenómeno urbano. Sin embargo, las fuentes literarias nos indican que en el año 39 a.C. los cerretanos debieron ser sometidos por la fuerza, en unos combates lo suficientemente significativos como para ser recogidos por diversos autores romanos (en especial, Dión Casio, Hist. Rom. 48.42). Se trata de unos combates muy tardíos, si tenemos en cuenta que prácticamente desde Catón no había habido enfrentamientos en el NE Peninsular que no fueran debidos a enfrentamientos civiles, lo que ha llevado a los investigadores a proponer diversas explicaciones: o bien se trata de una rebelión tardía de un pueblo ya sometido, o bien hace referencia a unos ceretanos más occidentales, 
que no pueden corresponder a los habitantes de la Cerdaña y comarcas afines. ${ }^{21}$ Veamos los datos de los autores antiguos.

Es Dión Casio (Hist. Rom. 48.42) quién nos indica cómo bajo el mando de Domicio Calvino, legado de Octavio en Hispania, hubo enfrentamientos con los ceretanos. Inicialmente las tropas romanas sufrieron un serio revés, cuando su lugarteniente fue abandonado por las tropas durante una emboscada. Esta escaramuza también fue recogida por Veleyo Patérculo ( $H R$ 2.78), quien menciona a un centurión primipilo, Vibilius, al que Domicio hizo fustigar por haber huido deshonrosamente del combate. Según Dión, tras castigar a sus tropas -diezmando algunas unidades y castigando a un gran número de centuriones, entre ellos al primipilus - se retomaron los combates, derrotando fácilmente a los ceretanos. Se le concedió entonces un triunfo, recibiendo el oro necesario de las ciudades de Hispania (Dión Casio, Hist. Rom. 48.42). Sabemos también que Domicio Calvino acuñó como imperator denarios en Osca (RRC 532.1), no como moneda conmemorativa sino para el pago de las tropas y sus aliados, lo que parece indicar que los combates pudieron tener un teatro de operaciones algo más occidental, en el Pirineo aragonés más que en el catalán. ${ }^{22}$

Estas sorprendentes campañas coinciden en el tiempo con las actuaciones de Marco Agripa, mano derecha de Augusto, en la zona de la Aquitania (Apiano, $B C$, 5.92), e incluso en el 35-34 a.C. el propio Octavio intervino en los Alpes e Iliria. Algunos años después, en el 29 a.C., Mesala Corvino (App., Bell. Ciu. 4.38; Tib. 1.7.3-12) también efectuó campaña militares en Aquitania pero alcanzó a su vez la zona del río Aude, es decir, justo al norte de la actual comarca de la Cerdaña. Todos estos combates podrían indicar que, tras las guerras civiles, existió una voluntad de dominio de los territorios pirenaicos y peripirenaicos aún no controlados en el interior de unas provincias tan estratégicas como la Citerior y la Narbonense, y que quizás algunas comunidades ceretanas aún no habían sido plenamente sometidas. No sería una excepción: sabemos que también en los Alpes se iniciaron a partir de esta época diversas campañas de dominio de los territorios en manos aún de comunidades indígenas, como los Allobroges o los Salassi, que si bien cercanos a la órbita romana mantenían aún su autonomía, controlando incluso el franqueo de los pasos alpinos. El caso más evidente sería el valle de Aosta, donde en el 25 a.C. se derrotó a los Salassi para posteriormente fundar la colonia de Augusta Praetoria, Aosta, en una clara voluntad de dominio territorial.

Aunque no fuera directamente Octavio/Augusto quien efectuó estas operaciones pirenaicas, tanto Domicio como Agripa fueron personajes que se movían en su entorno, y ejercieron su poder como imperatores en nombre de Octavio, por lo que parece que -como en el caso Alpino- fue el futuro Augusto el verdadero motor de estos cambios. Los mismos astures y cántabros podrían dar fe de este cambio de estrategia, ya de carácter imperial. Los enfrentamientos con los ceretanos, pues, podrían responder a un intento de algunas comunidades más occidentales a escapar del dominio romano, un dominio quizás ahora más agresivo e intervencionista que en periodos anteriores, cuando el control laxo de las zonas de paso había sido suficiente. Bajo el imperio,

21 Olesti-Mercadal 2005; Amela 2011.

22 Olesti-Mercadal 2005; Amela 2011. 
el control de las comunidades montañesas fue mucho más férreo. Ello implicaría el cambio en las formas de ocupación de estas áreas, y el establecimiento de un nuevo modelo de control territorial. La arqueología parece confirmarlo: poco después de mediados del s. I a.C. tanto el oppidum del Castellot de Bolvir como el Turó de Baltarga se abandonan, aparentemente de manera pacífica y sin destrucción.

En ambos yacimientos, además, dos afortunados hallazgos monetarios parecen marcar un perfil cronológico muy similar: en el Castellot la reciente localización de una moneda de la ceca de Celsa del año 45-44 a.C., ${ }^{23}$ y en Baltarga un denario de $C n$. Mag. Imp. 46-45 a.C.; RRC 471/1, así como otro de Petillius Capitolinus, 43 a.C., RRC 487/1, parecen marcar el final de la ocupación de estos establecimientos, cerca del año 40 a.C. Tan sólo Llívia mantienen su continuidad, y no casualmente será en este punto donde se fundará en época de Augusto la futura ciudad de Iulia Livica. En otras palabras, el sistema que desde como mínimo mediados del s. II a.C. se había implantado en esta región pirenaica, que implicaba una pequeña presencia militar - praesidia-sobre los principales establecimientos indígenas, desapareció aproximadamente hacia el 40 a.C., coincidiendo con el momento álgido de presencia militar en la región-como lo demuestra el sometimiento de los ceretanos por Domicio Calvino en el 39 a.C.-- Se plantean aquí diversos interrogantes, hoy por hoy aún de difícil solución: los hechos del 39 a.C., ¿mostraron las limitaciones de este sistema de control, y por ello se abandonaron los establecimientos? ¿Fueron quizás las operaciones vinculadas al sometimiento de los ceretanos el último momento en que estos centros fueron operativos? O quizás, más posiblemente, ¿tras la victoria decisiva sobre los ceretanos, ya no fue necesario el modelo logístico y militar propio del periodo anterior, y se dio paso a un nuevo sistema, que podríamos ya calificar de urbano? Nos inclinamos por esta última posibilidad.

\section{Hacia un nuevo modelo territorial: la urbanización augustea}

Tal como había ocurrido en la zona de los Alpes, también en el caso ceretano el fin de los últimos combates coincidió con la fundación de los primeros núcleos urbanos: en el territorio de la Cerdaña la nueva ciudad fue Iulia Livica, la actual Llívia. ${ }^{24}$ Las fuentes literarias son claras en destacar la intervención directa o indirecta de Augusto en estas fundaciones. Para el caso de los ceretanos, Plinio nos indica cómo en época de Augusto (recordemos que su información procede del llamado mapa de Agripa) los Cerretani gozaban del derecho latino, y presentaban los epítetos de Iuliani atque Augustani, en una referencia clara a una promoción jurídica de esta comunidad: $L a-$ tinorum (...) Ceretani qui Iuliani cognominantur et qui Augustani (Plin., N.H. 3.22). Además, el mismo epíteto de la ciudad en Ptolomeo, Iulia Livica, nos lleva en similar dirección.

23 Se trata de un ejemplar de la $8^{\mathrm{a}}$ emisión, bilingüe (GARCíA-BELlido - BLÁzQUEz 2001, 237).

24 Ptolomeo (Geogr. 2.6.68) es el único autor de la Antigüedad Clásica que documenta la existencia de Iulia Livica, la sola polis conocida entre los Cerretani. 
La arqueología puede ayudarnos a comprender mejor esta intervención.

En el último cuarto del s. I a.C., sobre el solar de la Libia de época pre-romana y republicana, se efectuaron unos amplios aterrazamientos que prepararon el espacio necesario para el nuevo centro urbano. Se trata de una construcción ubicada al pie del Puig del Castell, el probable solar del oppidum indígena, y que urbanísticamente corresponde a dos áreas bien diferenciadas. Por un lado, un amplio espacio público, con un edificio porticado, simétrico, que los recientes trabajos arqueológicos han permitido identificar como un notable fórum. ${ }^{25}$ Por otro lado, una parte residencial y productiva, con una orientación ligeramente diferente -adaptada a las curvas de nivel del piedemonte- de carácter claramente privado.

El fórum presenta unas medidas de 42,50 m este-oeste y unos 35 m conservados norte-sur, con un ámbito lateral ligeramente excéntrico que coincide plenamente con la distribución y las medidas del forum augusteo de Ruscino, en el Rossellón. Se ha podido identificar un edificio en el ángulo nororiental, una probable curia, decorada con pilastras, y que se abría al porticado que rodeaba al conjunto. Quizás lo más sorprendente, sin embargo, es el programa decorativo del fórum, caracterizado por el uso abundante de mármoles de importación. Destaca por ejemplo un fragmento de estatua en mármol de Carrara que corresponde a un torso desnudo, de tamaño algo superior al natural, y que ha sido interpretado como un personaje ideal o divinizado, quizás miembro de la familia imperial. ${ }^{26}$ De la misma estatua se conserva un fragmento de brazo, otro fragmento de torso con relieve inciso, y hasta 32 fragmentos informes, también de mármol, que parecen haber formado parte de estatuas. El conjunto decorativo se completaba con fragmentos de mármol de Luni-Carrara, placas decorativas uniformes (crustae) de La Pene Martín, Chentou, Skyros, Saint Béat, Rouge Llenguadoc, "Portasanta", Pavonazetto y Vilafranca de Conflent, y finalmente piezas de opus sectile también regulares de piedra calcárea marmórea (polombino). En resumen, se trata de un conjunto de materiales de construcción y decoración de carácter marmóreo, importados de canteras mediterráneas tanto occidentales como orientales, que podríamos considerar lujosos, y cuyos costes de adquisición y de transporte debieron de ser sin duda muy elevados. No podemos olvidar que la importación de mármoles arquitectónicos fue siempre costosa en el mundo romano, y muy limitada a las áreas costeras o de acceso fluvial, por lo que su presencia en este altiplano pirenaico, con un difícil transporte terrestre, sin duda nos indica el gran esfuerzo inversor que implicó la fundación y monumentalización de la ciudad. Finalmente, en las últimas excavaciones, llevadas a cabo por J. Guardia, se han localizado diversos fragmentos de decoración plástica en yeso, así como bloques de arquitrabe decorados e incluso un ara en granito. ${ }^{27}$ No es posible datar con precisión estos elementos arquitectónicos y decorativos, pero no hay duda de la cronología original del edificio, augustea, y si

25 GuARDia ET ALII 2014. Se trata de los trabajos emprendidos en el marco del proyecto "El fòrum de la ciutat romana de Iulia Libica" dirigido por los profs. Josep Guitart y Oriol Olesti, y con la participación de los investigadores C. Carreras y J. Guardia. Presentamos en este artículo unos primeros resultados de los trabajos del verano 2013, y agradezco a J. Guardia, J. Guitart y C. Carreras la posibilidad de contar con estos datos.

26 GutiÉrREZ-RodÀ, 2012.

27 Guardia ET ALII 2014. 
bien es posible que algunos elementos pudieran corresponder a fases posteriores, el esfuerzo inicial monumentalizador - muy coherente- debe atribuirse a su periodo de gobierno.

Por lo que respecta al sector privado, responde a una organización planificada del espacio, con muros de contención en sentido noroeste/sureste, que permitieron la construcción de diversos espacios domésticos y productivos. Ya de la primera mitad del s. I d.C., en lo que sería una segunda fase constructiva, se conoce una habitación con hypocaustum, junto a la cual se conservaron restos de la cámara de combustión. No conocemos el pavimento de esta habitación calefactada, aunque la localización en un vertedero situado a 20 metros, de numerosos fragmentos de mosaico bícromo y tubuli, sugieren la posibilidad de que se tratara de unos pequeños baños urbanos, que se amortizaron durante el s. II d.C. El resto de ámbitos documentados (un mínimo de seis, algunos con estucos pintados), muestran espacios domésticos con hogares, canalizaciones y áreas de producción (organizados en torno a un posible patio interno), donde destaca la localización de algunos materiales significativos tales como restos de producción de vidrio, morteros, un molino de basalto, ostras y materiales cerámicos de notable calidad. De nuevo, serían productos notables en una ciudad augustea costera, pero sorprendentes en una zona pirenaica, pues productos como las ostras parecen implicar su llegada a la ciudad vivas, para un consumo local claramente lujoso.

Finalmente, es también destacable la existencia de unas producciones locales de piezas de vidrio y de cerámicas de engobe en la ciudad (cuyos hornos fueron destruidos en el sector de Cal Barrié, Llívia), productos locales que han sido localizados en diversos establecimientos rurales, y que confirman la existencia de una red regional de producción y aprovisionamiento de productos artesanales, indicativos de una población dinámica y emprendedora.

La coincidencia de una cronología augustea para las estructuras urbanas, y del epíteto Iuliani atque Augustani de Plinio y de Iulia Livica en Ptolomeo, permiten atribuir a Augusto la fundación de la ciudad, un probable municipio de derecho latino si tenemos en cuenta la filiación latina de los Cerretani y la política augustea de promoción al derecho latino de amplios sectores provinciales, tanto en la Tarraconense como en la Narbonense. ${ }^{28}$ Es cierto que no tenemos ningún testimonio epigráfico de magistratura u ordo decurionum, pero la aparición de la ciudad en la lista de Ptolomeo, así como la cronología del fórum y de los epítetos documentados, nos habla de una comunidad privilegiada, autónoma, donde el derecho latino parece el estatuto más probable, dada la latinidad de los ceretanos. Este probable municipio latino fue el resultado de un proceso de integración social y económico que sin duda se inició en los s. II-I a.C., y que hicieron a los ceretanos un pueblo pirenaico especialmente interesante a los ojos de la administración romana, pero sin duda respondió también a la voluntad de organizar a partir del modelo urbano a unos territorios hasta entonces sin urbanizar.

28 García 2008. 


\section{La urbanización como etapa final de integración}

La civitas no era tan sólo una célula básica para la administración provincial, sino que la creación de su urbs, un núcleo urbano que concentrase los edificios religiosos y administrativos inherentes a la forma de vida romana, era también un mecanismo básico para la integración política y cultural de los provinciales, los ceretanos en este caso. Los nuevos ciudadanos -recordemos que el estatuto de municipio latino permitía a los miembros más destacados de la comunidad recibir la ciudadanía romana al finalizar el desempeño de los onerosos cargos magistrales- se convertían en los actores de un proceso de aculturación acelerado, que tenía en la ciudad, la urbs, el espacio aculturizador por excelencia.

Como indica el famoso texto de Tácito (Agric. 21), referido a la política del gobernador Gn. Agrícola en Britania (78-84 d.C.), el dominio de los vencidos no podía siempre garantizarse con la coerción y la violencia, sino que era necesario ofrecerles un proyecto de integración, de mejora, de promoción, y ese proyecto era la humanitas, la aparente civilización que permitía a las élites aceptar y disfrutar de los beneficios de las formas de vida romanas, ubicadas principalmente en el marco urbano. Tácito no puede ser más preciso al destacar el objetivo de esta política, la integración de las élites, los hijos de los jefes, el verdadero motor de la sumisión consensuada. Este proyecto se plasmaba en el espacio por excelencia donde desarrollar la humanitas, la ciudad, y los instrumentos para conseguirlo eran bien evidentes: atraer a las élites indígenas a las actividades de los pórticos -es decir, el espacio de discusión y actividad política por excelencia de los foros-, los baños -el espacio de la convivencia ciudadana-, y las domus, es decir, las lujosas casas urbanas donde se desarrollaba la vida privada, que implicaba sin duda las relaciones de clientela y patronazgo típicas de las grandes familias provinciales.

No es ninguna casualidad que sean precisamente estos tres espacios los que tengamos bien identificados en Iulia Livica, la pequeña ciudad pirenaica: el pórtico del fórum, donde se desarrollaba la carrera política de los ciudadanos, unas pequeñas termas -no sabemos si públicas o privadas, pero en cualquier caso necesarias para completar el ritual de la humanitas - y finalmente las lujosas casas privadas, donde se desarrollaban los explícitos banquetes que Tácito menciona, y que en Llívia tenemos documentados en la presencia de ostras, anecdótica si se quiere, pero significativa de la adopción de formas culinarias y de representación privada propias ya de una élite plenamente integrada.

A esta humanitas privada, debía añadirse el esfuerzo político por fomentar su desarrollo. En el caso británico, es clara la referencia de Tácito a la colaboración directa del gobernador en la construcción de tres elementos claves para la urbs: templos, foros y domus, elementos que de nuevo directa o indirectamente tenemos documentados en Llívia (aunque no conocemos la ubicación del templo, posiblemente bajo la actual iglesia parroquial, el hallazgo de una escultura representando un personaje divinizado no deja demasiadas dudas acerca de su existencia). No se trata de un fenómeno espontáneo indígena, sino que la propia administración romana favorece 
la construcción de los espacios urbanos, contribuyendo así a la consolidación de la célula básica de integración social y política.

Este proceso de integración puede ser identificado especialmente a partir de los datos epigráficos, pero en el caso de la Cerdaña desgraciadamente tan sólo conocemos 6 inscripciones. Así, procede de las excavaciones del foro de Llívia una inscripción (la única conocida hoy por hoy en la ciudad) de finales del s. I inicios del s. II d.C., probablemente honorífica, donde se menciona un Manli(us), un nomen gentil frecuentemente documentado en el sur de la Galia, y que algunos autores han puesto en relación a la actividad del procónsul de la Narbonense L. Manlio, quién ya vimos que actuó en el área pirenaica. Podría tratarse probablemente de un personaje notorio de la ciudad, quizás un magistrado, honrado en el área del foro. ${ }^{29}$ Más significativa parece en cambio la inscripción en mármol de Carrara procedente del monumento funerario de Prats de Cerdaña, a unos $15 \mathrm{~km}$ de la ciudad, que correspondió a un rico personaje enterrado junto a su finca rural. No conocemos su nombre, pero en cambio la mención al stipe(ndiorum) hace referencia a un más que posible veterano (IRC III, $189,190)$. Junto a su tumba, se halló también una incineración femenina que presentaba como ajuar una espectacular cadena de oro - con un cierre en forma de cabeza de serpiente- y los arreos en bronce de un caballo, todos ellos indicios de un personaje de rango privilegiado, y que posiblemente deban vincularse a la finca de un linaje aristocrático, quizás vinculada al ejército. Junto a estos indicios de grupos oligárquicos locales, conocemos también la presencia de grupos dependientes, documentados en una inscripción votiva hallada en Angostrina (IRC III, 188), una zona de aguas calientes cercana a Llívia, que menciona a Gaius P(ompeius?) Polibius, es decir, un individuo con cognomen griego que probablemente debemos considerar un liberto. Finalmente, conocemos a un Marcelus Gaius documentado en un grafito rupestre en Err, localizado junto a otros grafitos rupestres ibéricos, del cual desconocemos su cronología ${ }^{30}$ La mala ordinatio del nombre, con el nomen antes que el praenomen, y su ubicación en un contexto votivo de tradición indígena, nos hace pensar en un posible indígena romanizado, es decir, un miembro poco destacado de la sociedad ceretana alto-imperial.

\section{La explotación de los recursos pirenaicos en el Alto Imperio}

Una ciudad privilegiada, unas élites urbanas con notables indicios de riqueza, un programa monumental rico en mármoles, una familia rural con un rico mausoleo. ¿De dónde procedían todos estos recursos? Las fuentes literarias nos dan algún indicio sobre el territorio ceretano. Es Estrabón (Geogr. 3.4.11) quien se refiere a los valles centrales del Pirineo, perfectamente habitables, que ocupaban los Cerretanoi, en los que obtenían grandes beneficios con la producción de pernae, jamones probablemente curados en sal. Sabemos que las pernae Cerretanae se exportaban a Italia y gozaban de notable prestigio, pues así lo indica Marcial (Epigr. 13.54). Parece claro

29 RodÀ-Olesti, en prensa.

30 FERrER 2013. 
que durante los s. II y III continuó su producción y exportación a diversos puntos del Imperio, pues las pernae ceretanas aparecen en el Edictum de Pretiis de Diocleciano (4.1.8), lo que indica que al menos hasta principios del s. IV la Cerdaña estuvo integrada en las redes comerciales del Imperio y sus jamones siguieron siendo valorados.

Esta vocación ganadera está en parte contrastada por la continuidad de algunos establecimientos pastoriles, como l'Orri d'en Corbill. Así, en la cabaña 82, ubicada a $1.950 \mathrm{~m}$ de altura, se documentó un nivel del s. I d.C., con algunos fragmentos de T.S. sud-gálica. ${ }^{31}$ También en el cercano abrigo 83, un conjunto de bloques graníticos que fueron adaptados como hábitat, una datación C14 confirma una ocupación en torno al cambio de era. Ambos establecimientos muestran la continuidad de explotación de los pastos de verano. Es difícil vincular estos establecimientos dedicados al pastoreo de altura, indicativos de la transhumancia vertical, a la explotación de los suidos, un tipo de animal que más bien pasta en torno a las áreas agrícolas y suburbanas, pero no es en absoluto descartable, puesto que existen paralelos etnográficos de desplazamiento de suidos a áreas de pastoreo.

La producción de pernae haría necesario un importante aprovisionamiento de sal, elemento clave en cualquier sociedad ganadera. Aunque existen algunas fuentes de agua salada en el área pirenaica -por ejemplo el Salí de Cambrils, Solsonés-, es más probable que la sal utilizada en la Cerdaña procediera de las minas de sal de Cardona, como vimos ya mencionadas por Catón. Existe una importante vía medieval, el "camí Cardener" o vía de la sal, que desde Cardona pasando por Solsona se dirigía a la Cerdaña a través de la Vall de la Vansa, de cuyo origen antiguo existen pocas dudas.

Los datos paleoambientales conocidos muestran la continuidad de la presencia antrópica en la alta montaña, pero con una cierta pausa en época augustea. Así, por ejemplo, los trabajos de G. Jalut en el Pla de Salines (Cerdaña), a 2.200 m, muestran cómo el periodo augusteo supone un incremento de la masa forestal, en especial el pino y el roble, pero pronto, en torno a mediados del s. I d.C., se recupera y estabiliza una notable presencia antrópica, que reduce de nuevo la cobertura forestal. ${ }^{32}$ Este equilibrio entre bosque y pasto, indicativo de actividad ganadera, se mantiene claramente hasta aproximadamente el s. III d.C., cuando se inicia un nuevo periodo de actividad antrópica más agresiva, documentada por fuertes oscilaciones entre especies arbóreas, como el pino y el roble, que parecen fuertemente interconectadas (el incremento de una coincide con la reducción de la otra, lo que podría ser indicativo de una tala selectiva). Estos indicios de silvicultura coinciden con la aparición de nuevas especies vegetales, como cereales y plantago, indicios de una actividad agrícola en cotas más bajas pero no muy alejadas, sin paralelo en el periodo anterior, y que testimonian el incremento de la actividad antrópica en la media y alta montaña ceretana.

En la zona de Enveig (Pla de l'Orri), se confirman unos resultados parecidos. Así, los siglos II-I a.C. son el periodo de menor presencia antrópica en las cotas altas, siendo el momento donde los porcentajes de pino son más elevados y se reducen los indicios ganaderos, como poacea. Ello coincide sin embargo con la presencia de nuevas especies en áreas inferiores, como la viña y los cereales. Durante los s. I y II d.C. esta

31 RENDU 2003.

32 JALUT 1974. 
escasa actividad se mantiene, y deberemos esperar al s. IV d.C. para documentar un cambio de tendencia, y una fuerte actividad de deforestación. En el cercano sondeo de Gros Roc se confirma esta fuerte antropización a partir del s. III d.C., con claros indicios pastoriles.

Una evolución similar se observa en otra área de estudio, el lago de Burg (1.821 $\mathrm{m})$, en el Pallars, ${ }^{33}$ también en torno a los $2.000 \mathrm{~m}$, donde de nuevo en torno al cambio de era se documenta un descenso de la intervención humana (con la aparición, sin embargo, de nuevas especies cultivadas en cotas más bajas, como el castaño y el nogal), que se recupera fuertemente a partir del s. II d.C., con una nueva deforestación y la presencia de especies como poacea, plantago. Sorprende en Burg que también la deforestación es selectiva: el abeto se reduce drásticamente a partir del año 100 d.C., en lo que parece una gestión silvícola muy evidente, mientras que las demás especies se empezarán a ver afectadas tan solo a partir del 200 d.C. Una información parecida nos ofrecen los datos del polen de València d'Aneu, de donde se deduce una gestión compleja del bosque, con disminución de la biomasa del bosque, es decir, la reducción de plantas en su interior, pero un mantenimiento de la cobertura arbórea, en lo que podríamos calificar de dehesa o bosque antrópico.

En resumen, los diversos estudios paleo-ambientales realizados en la zona coinciden en señalar un inicial retraimiento de la actividad antrópica en torno al cambio de era, coincidiendo por tanto con la actividad augustea, pero una posterior recuperación de la actividad en las cotas altas en los siglos I y II d.C., indicativos de una gestión compleja de los recursos forestales y una posible recuperación de la actividad ganadera.

El interés por la leña no puede sorprendernos. Aunque conocemos muy mal la explotación de la madera en época romana en Hispania, por falta de estudios sistemáticos, unos primeros resultados han mostrado cómo a lo largo del s. II d.C. las ciudades costeras y del NE peninsular requirieron de especies procedentes de cotas medias, siendo insuficientes los recursos leñosos procedentes de los bosques más inmediatos. Incluso en el área del Pirineo central conocemos por el Itinerario de Antonino la existencia de un Forum Ligneum en la vía que de Iacca se dirige al Summo Pyrenaeo, es decir, un foro de la leña, un punto de comercio y mercado de este preciado recurso (It. Ant. 452.10). No se trataría tan sólo de leña para la construcción o como combustible (por ejemplo en forma de carbón), sino que otros usos de la leña son bien conocidos por las fuentes antiguas, y nos muestran la complementariedad y complejidad de las actividades silvicultoras. Plinio por ejemplo documenta también la importancia del Boj, Buxus, pirenaico (H.N. 16.28.71).

Mejor documentada ha sido la producción de pez, una resina de pino muy utilizada en época romana para la impermeabilización. Una de sus aplicaciones fue la impermeabilización de navíos, pero quizás incluso fue aún más importante su utilización en la impermeabilización de envases, como ánforas y dolia. ${ }^{34}$ No debemos olvidar, sin embargo, que la resina se utilizaba también en la antigüedad para aromatizar algunos vinos, y por ello nos aparece frecuentemente vinculada a la producción vi-

33 PÉLACHS ET ALII 2009.

34 Orengo et aLII 2013, 803. 
nícola, como nos indica el mismo Plinio (N.H. 23.24). Para producirla era necesario calentar a temperatura controlada los troncos de pino, extrayendo la resina hacia una canalización que permitía drenar el producto. La especie de pino más apropiada era el pinus mиgo que crece precisamente en cotas altas, entre 1.600 y $2.400 \mathrm{~m}$ de altitud.

Recientemente, en el Valle del Madriu (Andorra) - un valle directamente vinculado a la Cerdaña, aproximadamente a un día de camino de Llívia-, se han excavado diversos hornos romanos de producción de pez, ubicados en torno a los $2.200 \mathrm{~m}$ de altura. ${ }^{35} \mathrm{Se}$ trata de al menos un conjunto de 4 hornos alto imperiales, y alguno posterior, con dataciones $\mathrm{C} 14$ de abandono de mediados del s. II d.C., que podrían indicar un inicio de producción en torno a mediados del s. I a.C. El mejor conservado, el horno Pla de l'Ingla III, de unos dos metros de diámetro y que todavía conservaba el canal de extracción, apareció con una última carga de madera preparada, consistente en troncos de pinus mugo, como ya hemos dicho la especie de pino más interesante para la producción de pez. El resto presentaba indicios de la utilización de pinus unciata.

Es interesante la coincidencia entre el funcionamiento de los hornos y la transformación de los bosques cercanos. Precisamente es a mediados del s. I a.C., el probable inicio de la producción de pez, cuando se documenta en los sondeos palinológicos cercanos (Bosc dels Estanyons) el inicio de la disminución del pino, una disminución que se acentúa fuertemente a mediados del s. II d.C., probablemente el momento álgido en la producción de resina. ${ }^{36} \mathrm{La}$ tala selectiva de pinus, sin embargo, no provocó la desaparición de esta especie, sino que se permitió cíclicamente su recuperación, indicando una inteligente gestión forestal. La dimensión de la producción, con unos 6 hornos documentados en total en el Madriu, permiten pensar en una producción excedentaria, aunque de una dimensión modesta, puesto que no funcionaron todos al mismo tiempo, ni de manera continua. ${ }^{37}$ Las grandes áreas vitivinícolas del NE peninsular -como la Layetania o el ager Tarraconensis-, serían un buen mercado para esta resina pirenaica. La especie de pino más valorada para la producción de pez era el pinus mugo, que crece precisamente en cotas altas, entre 1.600 y $2.400 \mathrm{~m}$ de altitud, lo que explicaría la ubicación aquí de estos hornos. ${ }^{38}$

En resumen, los datos paleo-ambientales y arqueológicos permiten documentar cómo durante el Alto Imperio, progresivamente, hubo una reocupación en las áreas pirenaicas orientales de las cotas altas, indicios de una actividad forestal y pastoril especializada, sin duda temporal, pero que permitió la generación de algunas producciones (pernae, quizás también lana, pez, productos leñosos y/o carbón vegetal) que tuvieron una difusión importante a nivel provincial, e incluso imperial. Ello implicaba la existencia de una red viaria notable, que permitía el aprovisionamiento de ciudades como Llívia (bien demostrado a partir de productos como los mármoles o las propias ostras), pero también la exportación de productos de alto valor comercial, como las pernae y el pez.

\footnotetext{
35 ORENGO ET ALII 2013.

36 ORENTGO ET ALII 2013, 807.

37 Orengo ET ALII 2013, 804.

38 OREngo ET ALII 2013, 811.
} 
También las fuentes nos hablan de un recurso poco valorado, pero presente en las áreas pirenaicas, y que además se refieren directamente a la actividad de Augusto: las aguas termales. Se trata en primer lugar de la referencia de Plinio (N.H. 31.4) a la importancia de los baños de aguas termales en el área pirenaica, que hace extensiva a la Aquitania, y que tiene su constatación arqueológica en las diversas fuentes termales con indicios de utilización en época romana (Ax les thermes, Bagneres de Bigorre, etc.). Crinágoras (Antología Palatina 9.419), menciona explícitamente cómo con la presencia de Augusto fueron conocidas algunas fuentes termales del Pirineo, que según él los indígenas no habían utilizado antes. Esta presencia de fuentes termales en la vertiente norte pirenaica tiene también su traslación al lado sur, donde son numerosas las fuentes termales que presentan indicios de utilización en época romana. En el caso de la Cerdaña, por ejemplo, conocemos el hallazgo de monedas romanas en Vilanova de les Escaldes, a escasos tres kilómetros de Llívia, y también cerámicas romanas en Cáldegues, dos kilómetros al sur de la ciudad romana. Estos y otros topónimos vinculados al latino calidae, parecen también ir en la línea de una cronología romana.

Un último elemento, aún en estudio, podría completar esta batería de productos pirenaicos explotados en época alto-imperial: el oro aluvial del Segre. No podemos entrar en este artículo a fondo en la cuestión, pero bastará con decir que diversos trabajos desarrollados por nuestro equipo en los últimos años en el valle alto del Segre, ${ }^{39}$ han permitido documentar la existencia de importantes depósitos auríferos en las terrazas miocénicas de la Cerdaña y el Alt-Urgell. Se trata de oro secundario, que en esta región presenta un grado de riqueza no muy elevado, pero parecido al de otras zonas auríferas explotadas por Roma. Sobre estos depósitos miocénicos hemos estudiado diversos conjuntos de erosión antrópica, de origen hidráulico, que presentan morfologías plenamente coincidentes con las huellas de las minas aluviales de época romana. Incluso en la zona de All (Isóvol, Cerdaña), pudimos excavar un depósito hidráulico conectado directamente con el frente de erosión, en el que aparecieron algunas piezas de cerámica romana, aunque no permitieron una datación precisa del conjunto. Estos elementos morfológicos y arqueológicos deben combinarse con la existencia de diversas piezas de oro en la Cerdaña (incluida la cadena de oro de la necrópolis de Prats, ubicada a escasos 1,5 km de las minas de All), y con el reciente hallazgo en el Castellot, a mediados del s. II a.C., de un taller polimetalúrgico, donde hemos documentado con seguridad que se trabajó el oro. ${ }^{40}$

Es aún pronto para establecer conclusiones, pero debemos destacar que la vida de la ciudad de Llívia coincide plenamente con el periodo de funcionamiento de las minas de oro aluvial hispanas, es decir los s. I-II d.C., y ello permitiría explicar la corta pero notablemente rica vida de la ciudad. En cualquier caso, estamos seguro que la existencia de oro pirenaico, ya destacado por Plinio (N.H. 3.30; 4.112), no pasó inadvertido a los romanos, que de una u otra manera llevaron a cabo su explotación (una mina de oro en roca, de época tardía, ha sido excavada en el Capcir, comarca

39 Morera et ali 2012, y Olesti et ali en prensa.

40 Montero et Ali, en prensa. 
vecina de la Cerdaña). ${ }^{41}$ Es en este sentido indicativo que en época islámica fuese conocido el oro del Segre como un recurso importante, y que precisamente Llívia fuera también en este periodo - breve sin duda- una guarnición mencionada por las fuentes musulmanas. ${ }^{42}$

La explotación del oro en el Pirineo Oriental en el Alto Imperio permitiría cerrar el círculo de unos territorios organizados, explotados y plenamente integrados a la economía imperial, que nos alejan de la visión de un mundo romano poco interesado en las áreas montañosas, y que nos permiten conocer el interés por unos territorios complementarios, diversos, sin duda también necesarios para el buen funcionamiento de un sistema complejo como el del mundo romano. Como en tantas otras cosas, $\mathrm{Au}-$ gusto no fue el primero en identificar el interés estratégico y económico de estas áreas pirenaicas, pero sin duda fue pieza fundamental en la consolidación de su dominio, fomentando mediante la urbanización y la promoción jurídica la integración de estas comunidades al nuevo modelo imperial romano. Fue de nuevo un proceso exitoso que, pese a la corta vida urbana de Iulia Livica, consolidó las estructuras económicas y sociales hasta bien entrado el Bajo Imperio en unos territorios que habíamos considerado tan alejados del interés romano.

\section{Bibliografía}

AMELA, L.

(2002): Las clientelas de Pompeyo Magno en Hispania, Barcelona.

(2011): “Cn. Domicio Calvino y los ceretanos”, Hispania Antiqua 35, 43-65.

Asín, M. (1934): “Un códice inexplorado del cordobés Ibn Hazm”, Al-Andalus 2/1, 1-53.

Beltrán, F. - F. Pina (1994): "Roma y los Pirineos: la formación de una frontera", Chiron 24, 103-133.

Caunet, B. (2005): L'or de Tolosa. L'exploitation des gisements auriferes de la Gaule dans L'Antiquité, Toulouse.

CAmpamajo, P. (2012) : Ces pierres qui nous parlent: Les gravures rupestres de Cerdagne (Pyrénées orientales) de la fin de l'Âge du fer à l'époque contemporaine, Perpignan.

Colominas, L. (2013): Arqueozoología y Romanización: Producción, distribución y consumo de animales en el nordeste de la Península Ibérica entre los siglos $V$ ane- $V$ dne. BAR International Series, Oxford.

Cruz AndreotTi, G. (2002): "Iberia e Iberos en las fuentes histórico-Geográficas Griegas: una propuesta de análisis", Mainake 24, 153-180.

FERRER, J.

(2013): "Els sistemes duals de les escriptures ibèriques", Paleohispanica 13, 445-459.

(2015): "L'escriptura ibèrica a la Cerdanya: els abecedaris rupestres", Rev. ERA 1, 37-48.

GARCIA, E. (2008): "Reflexiones sobre la latinización de Hispania en época republicana”, [en] Hispaniae. Las provincias hispanas en el mundo romano, Tarragona, 377-391.

41 Cauvet 2005.

42 Obra de Ibn Hazam (Asin 1934). 
Garcia-Bellido, M. P. - C. Blázquez (2001): Diccionario de Cecas y pueblos hispànicos, 2 vols. Madrid.

Guardia, J. - J. Guitart - C. Carreras - O. Olesti (2014): "Prospecció geofísica i sondejos al forum de Iulia Livica", [en] Dotzenes jornades d'Arqueologia de les Comarques de Girona, Girona, 198-206.

Gutierrez, A. - I. RodÀ (2012): "El mármol de Luni-Carrara en la fachada Mediterránea de Hispania", [en] S. Keay (ed.), Rome, Portus and the Mediterranean, London.

Montero, I. - O. Olesti - J. Morera - O. Garcia (en prensa): "El taller metalúrgico del Castellot de Bolvir (II-I a.C.) y la presencia romana en el Pirineo", [en] VIII Congreso Internacional sobre minería y metalurgia históricas en el Occidente Europeo (Granada, 11-15 junio 2014), Granada.

Morera, J. - O. Olesti - J. Oller

(2012): "El Castellot de Bolvir (Cerdanya): ocupacions Certana, iberoromana i Alt-Medieval", Onzenes jornades d'Arqueologia de les Comarques de Girona, Girona, 125-134.

(2014): "El Castellot de Bolvir (Cerdanya): ocupacions Certana, iberoromana i Alt-Medieval", [en] Dotzenes jornades d'Arqueologia de les Comarques de Girona, Girona, 145-156.

Olesti, O.

(2000): “Integració i transformació de les comunitats ibèriques del Maresme durant el s.II-I a.C.: un model de romanització per a la Catalunya litoral i pre-litoral.”, Empúries 52, 5586.

(2014): Paisajes de la Hispania Romana. La explotación de los territorios del Imperio, Barcelona.

Olesti, O. - B. Cauuet - M. Viladevall - O. Mercadal - J. Morera - F. Christophoul, (en prensa): "The Roman Gold mines of the Eastern Pyrenees in Antiquity", [en] Wilson, A. (ed.), Roman Economy Project. Mining, Metal Supply and Coinage in the Roman Empire, Oxford.

Olesti, O. - O. Mercadal

(2005): "La Cerdanya: transformacions d'un poble i d'un paisatge pirinenc en època antiga", [en] Protohistoria et Antiqua Historia Pyrenaica. Actes del II Congrès Internacional Història dels Pirineus, Girona, 181-274.

(2010), “L'occupation romaine de la Cerdagne: transformations d'un paysage pyrénéen pendant l'antiquité", [en] Vermeulen, F. - C. Corsi (eds.), Changing Landscapes. The impact of Roman towns in the Western Mediterranean. Proceedings of the International Colloquium, Castelo de Vide - Marvão 15th-17th May 2008, Bologna, 129-140.

Olesti, O. - O. Mercadal - J. Morera - C. Crespo (2010): “El Castellot de Bolvir (Cerdanya): ocupacions Ceretana, iberoromana i alt-medieval", Tribuna d'Arqueologia 20092010, 281-315.

Oller, J. - J. Morera (2013): Memòria de les intervencions arqueològiques al jaciment del Turó de Baltarga (Bellver de Cerdanya), Servei d'Arqueologia de la Generalitat de Catalunya. Memoria inédita.

Orengo, H. - J. M. Palet - A. Ejarque - Y. Miras - S. Riera (2013): "Pitch production during the Roman period: an intensive mountain industry for a globalised economy?", Antiquity $87,802-814$. 
Pélachs, A. - J. Nadal - J. M. Soriano - R. Cunill - D. Molina (2009): “Changes in Pyrenean woodlands as a result of intensity of human occupation: 2000 years of metallurgy in Vallferera", Veget.Hist.Archeobot. 18, 403-416.

RENDU, C. (2003) : La montagne d'Enveig. Une estive pyrénéenne dans la longue durée, Perpinyà.

Rico, CH. (1997) : Pyrénées romaines: essai sur un pays de frontière (IIIe siècle av. J.-C.-IVe siècle ap. J.-C.), Toulouse.

RodÀ, I., Olesti, O. (en prensa): "Inscripció romana de Llívia", [en] Guàrdia, J. - O. Mercadal - O. Olesti (eds.), Llívia i la Cerdanya en època antiga, Tarragona. 